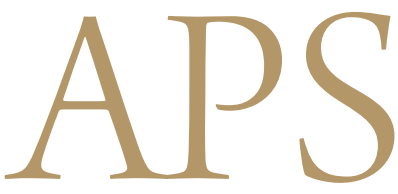

Archives of Plastic Surgery

\title{
Giant Lipoma of the Breast
}

\author{
Luis Ramírez-Montaño ${ }^{1}$, Erik Vargas-Tellez ${ }^{1}$, Walid L Dajer-Fadel ${ }^{2}$, Silvia Espinosa Maceda ${ }^{1}$ \\ Departments of ${ }^{1}$ Plastic and Reconstructive Surgery and ${ }^{2}$ Cardiothoracic Surgery, General Hospital of Mexico, Mexico City, Mexico
}

Lipomas are benign mesenchymal tumors that develop in areas of abundant adipose tissue. Due to the fatty composition of the breast, difficulties in diagnosis, treatment, and reconstruction are often encountered. We report a case of a 55-year-old female with a giant tumor of the right breast that comprised most of its mass, causing breast asymmetry. A thorough preoperative evaluation, followed by an uneventful difficult surgical resection and reconstruction, resulted in diagnosis of a benign lipoma. The case prompted this report because of its challenging size, location, diagnosis, and reconstructive solution.

Keywords Lipoma / Breast neoplasms / Breast diseases / Mammaplasty

\author{
Correspondence: \\ Luis Ramírez-Montaño \\ Department of Plastic and \\ Reconstructive Surgery, General \\ Hospital of Mexico, Oriente 180 \\ A \# 15, Colonia Ermita, CP 03590, \\ Delegación Benito Juárez, \\ Mexico City, Mexico \\ Tel: $+52-155394818$ \\ Fax: +52-155394818 \\ E-mail: luisrm82@gmail.com
}

No potential conflict of interest relevant to this article was reported.

\section{INTRODUCTION}

Lipoma is one of the most common benign neoplasms derived from fatty tissue. The incidence accounts for approximately $16 \%$ of all mesenchymal tumors [1]. They usually develop as wellcircumscribed, encapsulated masses with a doughy feel that is freely mobile underneath the skin. They can arise in any part of the body. In the breast, a diagnostic work-up is needed due to its varying history and clinical course, given the fact that they tend to be small in diameter. However, patients seek medical attention over their concerns with the size augmentation, disfiguration or asymmetry, not to mention the fear of malignancy, of a swelling mass. Breast asymmetry can result from unequal hypertrophy or neoplastic growth, leading fatty tumors to be clinically and radiographically difficult to differentiate from hypertrophy [2]. Giant lipomas are defined as lesions that have a diameter of at least $10 \mathrm{~cm}$ or a weight of more than $1,000 \mathrm{~g}$ [3]. We present an unusual case of a right breast giant lipoma that comprised most of its mass, causing asymmetry, that was associated with benign breast hypertrophy.

\section{CASE}

A 55-year-old otherwise healthy female arrived at our plastic surgery department with a diagnosis of benign breast hypertrophy, referred by the oncologist for reduction mammoplasty. She reported a progressive increase in her breast size over the previous 20 years, being more evident in the right side. Otherwise asymptomatic, she was concerned about the asymmetry of her breasts and the possibility of a cancerous tumor. A preoperative examination revealed a bilateral increase in breast size, with severe asymmetry based on marked enlargement of the right side. The ptotic breasts were soft and no palpable masses were identified (Fig. 1). There was no local heat sensation or manifestations of systemic disease. A preoperative screening mammogram showed no masses or other suspicious abnormalities. Benign breast hypertrophy associated with breast asymmetry was diagnosed, and reduction mammoplasty planned. Preoperatively, the patient was marked as for an inferior pedicle and Wise pattern reduction mammoplasty. Through an incision in the lateral vertical limb of the inferior pedicle, a 2,500 $\mathrm{g}$ lipoma of the right breast was removed, comprising most of its mass,

Copyright $(\odot 2013$ The Korean Society of Plastic and Reconstructive Surgeons

This is an Open Access article distributed under the terms of the Creative Commons Attribution Non-Commercial License (http://creativecommons.org/

licenses/by-nc/3.0/) which permits unrestricted non-commercial use, distribution, and reproduction in any medium, provided the original work is properly cited. 


\section{Fig. 1. Preoperative appearance}

Ptotic breasts with marked asymmetry. A large swollen right breast has a round contour; no palpable masses were identified. No abnormal skin changes were present. Benign breast hypertrophy associated with breast asymmetry was diagnosed.

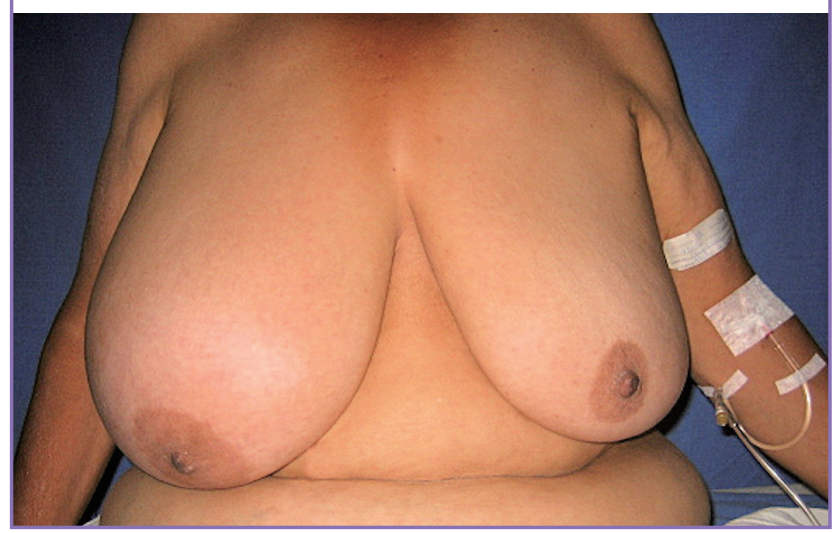

\section{Fig. 3. Excised specimen}

Morphologic examination of giant lipoma of the breast. A lipoma weighing 2,500 g, with $24 \mathrm{~cm} \times 20 \mathrm{~cm} \times 6 \mathrm{~cm}$ dimensions was excised.

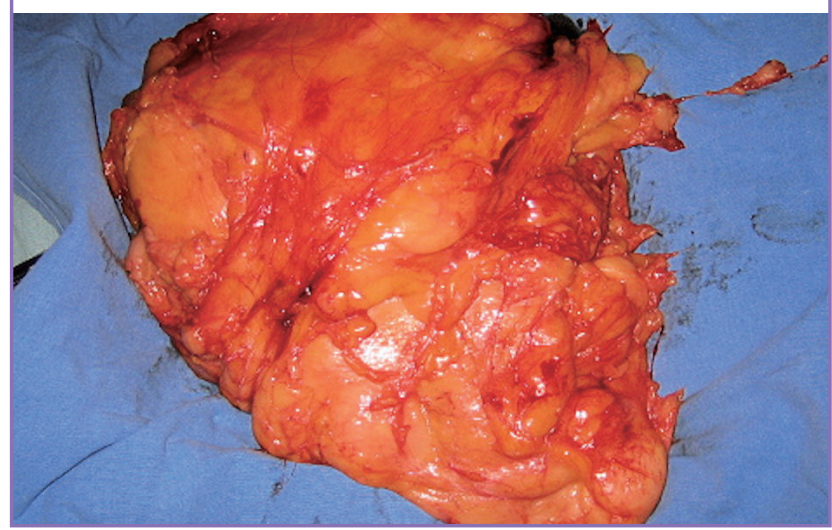

resulting in a volume deficit with excess skin (Fig. 2). The tumor had a subglandular location, and the atrophic breast glandular tissue was compressed anteriorly and inferiorly, displacing the nipple areola complex; a thin capsule created a clear demarcation between the tumor and glandular tissue. A morphologic examination demonstrated a wide uniform mass that measured $24 \mathrm{~cm} \times 20 \mathrm{~cm} \times 6 \mathrm{~cm}$ covered by a thin capsule (Fig. 3). Reconstruction proceeded with de-epithelialization of the redundant skin, and folding in the dermis and glandular tissue in the medial and lateral triangles, tacking them superiorly instead of resecting them to restore the volume deficit by autologous augmentation. No glandular tissue was resected. The contralateral breast was treated in a similar fashion, $800 \mathrm{~g}$ of tissue was resected for inferior pedicle breast reduction with no evidence of a tumor. In both breasts, upper pole fullness was achieved by plication of the upper de-epithelized and undermined flaps to the pectoralis major fas-

\section{Fig. 2. Removal of lipoma}

Inferior pedicle, wise pattern reduction mammoplasty. Through an incision, the lipoma, covered by a thin capsule, was removed. The tumor comprised most of the breast mass, resulting in a volume deficit with excess skin.

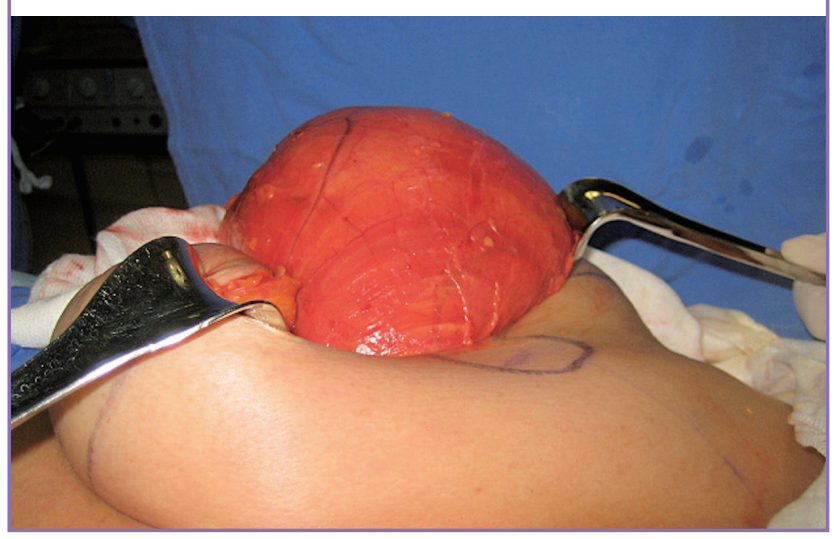

Fig. 4. Appearance at six months postoperatively

Symmetry and a good aesthetic outcome was achieved.

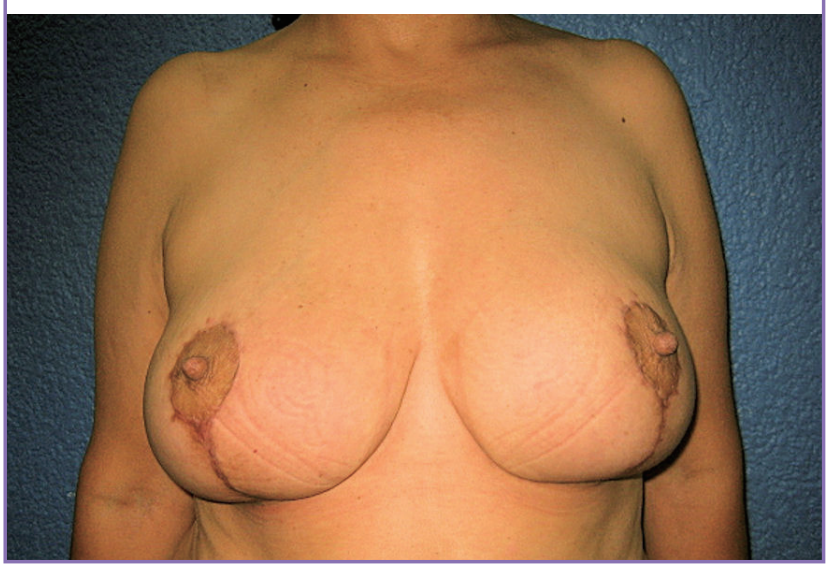

cia in a higher position relative to the breast meridian. Symmetry and viability of the nipple areola complex were achieved. After 6 months of follow-up in the outpatient clinic, a satisfactory outcome was shown (Fig. 4). The pathology results revealed a lipoma composed of benign adipocytes with no neural component or malignant transformation.

\section{DISCUSSION}

Lipomas are among the most common mesenchymal tumors and are usually benign, well circumscribed, and covered by a thin capsule, appearing in almost every region of the body with a prevalence of 2.1 per 1,000 people [4]. Twenty percent are located in the chest wall [5]. They can be sub-classified according to their etiology, histological characteristics, localization, and dimensions. The breast is a common site for this pathology; 
however, they tend to be small asymptomatic tumors [6].

Most cases of breast asymmetry and unilateral breast enlargement result from unequal physiological hypertrophy, but a neoplastic process should be suspected when the size discrepancy appears with obvious architectural distortion, making mandatory a thorough clinical and paraclinical evaluation. Although lipomas are considered by many to be a banal condition, they often cause diagnostic and therapeutic uncertainty, especially in the breast, because its normal fatty composition and the difficulty of distinguishing them from other benign or malignant lumps [7]. Physical examination is often of little diagnostic use, especially in large or deep tumors. The lack of a defined consistency and the preservation of the breast contour are common in a fatty tumor or benign hypertrophic breast [8]. The presence of missed lipomas during routine mammography in large postmenopausal patients' breasts have been reported. Simple radiography, ultrasonography, computed tomography, or magnetic resonance imaging can be used for definitive identification [7].

In this patient, the right breast was almost completely replaced by the lipoma. The physical findings and paraclinical studies failed, ultimately resulting in a misleading diagnosis. To our knowledge, this case is one of the largest breast lipomas reported in the literature.

Although total excision of a tumor is the definitive treatment for lipoma, neoplasms of this size and location that result in an unequally paired organ make reconstruction a great challenge for surgeons [9]. The size and shape of the contralateral breast should be considered in choosing the surgical strategy for an adequate reconstruction to achieve a good symmetrical result. Modifications of traditional mammoplasty techniques should be taken into account [10], but prosthesis, autologous augmentation, reduction, or mastopexy can be used to reach this goal.

In conclusion, lipomas of the breast are benign tumors with a very limited risk of malignant transformation; they are associated with an excellent prognosis after successful excision despite the fact that they can represent a great reconstructive challenge, especially in the symmetry and aesthetics of this paired anatomic structure. Preoperative evaluation requires a careful diagnostic workup due to its similarity to other pathologies, especially those associated with breast asymmetry and benign hypertrophy.

\section{REFERENCES}

1. Lanng C, Eriksen BO, Hoffmann J. Lipoma of the breast: a diagnostic dilemma. Breast 2004; 13:408-11.

2. Hall FM, Connolly JL, Love SM. Lipomatous pseudomass of the breast: diagnosis suggested by discordant palpatory and mammographic findings. Radiology 1987;164:463-4.

3. Sanchez MR, Golomb FM, Moy JA, et al. Giant lipoma: case report and review of the literature. J Am Acad Dermatol 1993;28:266-8.

4. Silistreli OK, Durmus EU, Ulusal BG, et al. What should be the treatment modality in giant cutaneous lipomas? Review of the literature and report of 4 cases. Br J Plast Surg 2005; 58:394-8.

5. Salvatore C, Antonio B, Del Vecchio W, et al. Giant infiltrating lipoma of the face: CT and MR imaging findings. AJNR Am J Neuroradiol 2003;24:283-6.

6. Hakim E, Kolander Y, Meller Y, et al. Gigantic lipomas. Plast Reconstr Surg 1994;94:369-71.

7. Dooms GC, Hricak H, Sollitto RA, et al. Lipomatous tumors and tumors with fatty component: $\mathrm{MR}$ imaging potential and comparison of MR and CT results. Radiology 1985; 157:479-83.

8. Rodriguez LF, Shuster BA, Milliken RG. Giant lipoma of the breast. Br J Plast Surg 1997;50:263-5.

9. Raemdonck D, De Mey A, Goldschmidt D. The treatment of giant lipomas. Acta Chir Belg 1992;92:213-6.

10. Elsahy NI. Correction of asymmetries of the breasts. Plast Reconstr Surg 1976;57:700-3. 